\title{
Effect of acute heat stress on adrenocorticotropic hormone, cortisol, interleukin-2, interleukin-12 and apoptosis gene expression in rats
}

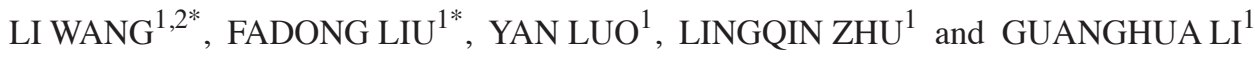 \\ ${ }^{1}$ Department of Physiology, School of Basic Medical Science, Ningxia Medical University; ${ }^{2}$ Department of Comprehensive \\ Medicine, The General Hospital of Ningxia Medical University, Yinchuan, Ningxia 750004, P.R. China
}

Received February 13, 2015; Accepted March 6, 2015

DOI: $10.3892 /$ br. 2015.445

\begin{abstract}
The aim of the present study was to investigate the effect of acute heat stress on the neuroendocrine and immunological function in rats. Male Sprague-Dawley rats were randomly divided into two groups and respectively exposed to heat $\left(32^{\circ} \mathrm{C}\right)$ or to room temperature $\left(24^{\circ} \mathrm{C}\right)$. After 7 days of heat exposure, the heat-stress rat model was established. The organ coefficients of the pituitary and adrenal glands were determined. The body temperature was measured by telemetry. The average contents of adrenocorticotropic hormone (ACTH), cortisol (Cor), interleukin-2 (IL-2) and IL-12 in serum were detected. The expression of apoptotic genes in the spleen was measured. The results showed that acute heat stress did not evidently affect the body temperature and body weight $(\mathrm{P}>0.05)$, but the exposure increased the organ coefficients of the pituitary and adrenal glands $(\mathrm{P}<0.05)$. Heat exposure significantly elevated the level of ACTH, Cor, IL-2 and IL-12 $(\mathrm{P}<0.05)$. The expression of caspase-3 and Bax were not changed significantly $(\mathrm{P}>0.05)$, while $B c l 2$ was reduced $(\mathrm{P}<0.05)$.
\end{abstract}

\section{Introduction}

Global warming is a challenge to human development, which causes irreversible changes to the ecosystem on the earth. Climate warming not only causes a negative effect to the human survival environment, but also brings serious damage to the health of human beings. In recent years, the

Correspondence to: Professor Guanghua Li, Department of Physiology, School of Basic Medical Science, Ningxia Medical University, 1160 Shengli Street, Yinchuan, Ningxia 750004, P.R. China

E-mail: ghlee0404@163.com

${ }^{*}$ Contributed equally

Key words: heat stress, hypothalamus-pituitary-adrenal axis, neuroendocrine, apoptosis effect of a continuous high temperature environment on health and well-being is receiving increasing attention (1). A high temperature environment as a source of stress triggers a series of stress responses of the body. It causes the imbalance of internal metabolism, damage to the tissue and organ, and fatigue (2). The imbalance of the body's heat may cause the heat-stress reaction (3), and the body's core temperature continues to rise due to the disorder of the heat balance. Body temperature is vital for the body to maintain the physiological function, as cell biological and enzymatic reactions are affected by the temperature. Cell damage will occur due to the denatured intraocular protein and enzyme induced by the raised core temperature. By measuring the body's core temperature of rats, the influence of heat exposure on the body's core temperature can be explored.

The hypothalamus-pituitary-adrenal (HPA) axis is the primary neuroendocrine system involved in the stress response (4). The HPA axis secretes adrenocorticotropic hormone (ACTH) and cortisol (Cor). The change of ACTH and Cor adapt to the adverse environment, which is the evaluated index for the degree of stress and plays an extremely important role in the body (5). The weight of the organs change under the state of stress (6), including the pituitary, adrenal and hypothalamus. In the present study, by testing the organ coefficient of the pituitary and adrenal glands, and by testing the levels of ACTH and Cor in serum, whether the high temperature environment $\left(32^{\circ} \mathrm{C}\right)$ caused the heat-stress response in rats was explored. Different types of stress can affect the immune function, such as psychological, cold, thermal and fear stress. Interleukin-2 (IL-2) is mainly produced by the active T cells and has a variety of functions in the immune system. IL-2 also affects the HPA axis, and its level can be used as an important index of cellular immune function (7). IL-12 enhances the activity of $\mathrm{T}$ cells and natural killer (NK) cells. These indicators were measured to explore the association between heat stress and immunological function.

In general, under the condition of heat stress, the damage to animal tissues and organs occurs; the damage to the immune organs is more serious. The apoptotic cells activate the immune response (8) and they also start an immune tolerance (9). Of note, numerous studies have shown that strong stress is harmful to the organs, tissues, cells and immune 
Table I. Sequence of oligonucleotide primers.

\begin{tabular}{llccr}
\hline Gene & \multicolumn{1}{c}{ Sequence $\left(5^{\prime} \rightarrow 3^{\prime}\right)$} & Length, bp & Temperature, ${ }^{\circ} \mathrm{C}$ & GenBank \\
\hline Caspase-3 & F: AGCTGGACTGCGGTATTGAG & 104 & 60 & NM_012922 \\
$B c l 2$ & R: GGGTGCGGTAGAGTAAGCAT & & & NM_016993 \\
Fax & $\begin{array}{l}\text { F: AGCCTGAGAGCAACCGAAC } \\
\text { R: AGCGACGAGAGAAGTCATCC }\end{array}$ & 159 & 60 & NM_017059 \\
$\beta$-actin & $\begin{array}{l}\text { F: TTGCTACAGGGTTTCATCCAG } \\
\text { R: TGTTGTTGTCCAGTTCATCG }\end{array}$ & 145 & 57 & NM_031144 \\
& $\begin{array}{l}\text { F: } \text { CACCCGCGAGTACAACCTTC } \\
\text { R: CCCATACCCACCATCACACC }\end{array}$ & 207 & 60 & \\
\hline
\end{tabular}

bp, base pairs; F, forward; R, reverse.

system, but occasionally mild stress is beneficial for the body in the heat acclimatization (10-12). Therefore, the present study aimed to explore whether the heat exposure is harmful to the body by detecting the expression of apoptosis genes in order to observe whether the cells are damaged under the moderate thermal environment and to discuss the influence of heat stress on the body by evaluating the changes of neuroendocrine and immune function.

\section{Materials and methods}

Animals and heat exposure protocol. Male Sprague-Dawley rats, weighing 180-200 g, were purchased from the Laboratory Animal Center of Ningxia Medical University (Ningxia, China). Rats were permitted to eat food ad libitum. The cycle of light and dark was 12:12 h (6:00 p.m.-6:00 a.m. as the light cycle and 6:00 a.m.-6:00 p.m. as the dark cycle every day). The rats were maintained in separate cages, with only $1 /$ cage. The cage size was $44 \times 27 \times 19 \mathrm{~cm}$. Room temperature was $24.0 \pm 0.1^{\circ} \mathrm{C}$ and relative humidity was $54 \pm 5 \%$. In the course of the experiment, cages were cleaned, and food and water were replaced at a random time every 2 or 3 days. Rats were anesthetized with intraperitoneal injection of phenobarbital sodium $(50 \mathrm{mg} / \mathrm{kg})$, and subsequently temperature sensors were placed and kept for 2 weeks for recovery. Sixteen rats were randomly divided into the control $(\mathrm{CN})$ and heat exposure (HE) groups ( $\mathrm{n}=8 /$ group). Rats in the $\mathrm{CN}$ group were fed at room temperature throughout the study. Rats in the HE group received a fixed 8 h (9:00 a.m.-5:00 p.m.) heat exposure process a day, and the exposure was finished inside the artificial climate chamber with a temperature of $32^{\circ} \mathrm{C}$ (relative humidity of $60 \pm 5 \%$ ). Following each exposure the rats were kept at room temperature. The heat exposure lasted for 7 days. The experimental procedures of the present study were approved by the Animal Ethics Committee of Ningxia Medical University and Use Committee, in accordance with the guidelines of the Council of the Physiological Society of China.

Body weight and viscera coefficient. The body temperature of the rats was collected by a wireless temperature sensor (TA10TA-F40; Data Sciences International, St. Paul, $\mathrm{MN}$, USA) and the processing was respectively analyzed in accordance with the day and night. Following the heat exposure, the body weight was analyzed. Each rat was anesthetized by intraperitoneal injection of phenobarbital sodium $(50 \mathrm{mg} / \mathrm{kg})$. The pituitary and adrenal gland were removed and weighed (XS105 Dual Range; Mettler-Toledo Inc., Columbus, $\mathrm{OH}$, USA) quickly, and subsequently the organ weight was calculated by the following formula: Organ coefficient = organ weight/animal body weight.

Detection of the serum ACTH, Cor, IL-2 and IL-12. Blood was collected from the inferior vena cava, centrifuged at 3,500 $\mathrm{x}$ g for $15 \mathrm{~min}$ and the serum was segregated for detection. Cor and ACTH levels were detected by radioimmunoassay. The serum IL-2 and IL-12 were detected using commercially available sandwich ELISA kits, which were the Rat IL-2 ELISA kit and Rat IL-12 ELISA kit (Chenglin Biotechnology, Beijing, China). All the detections were tested in accordance with the manufacturer's instructions. Absorbance was read at $450 \mathrm{~nm}$ (Bio-Rad 680; Bio-Rad Laboratories Co., Ltd., Hercules, CA, USA). The quantity of IL-2 in the serum was estimated from a calibration curve, which ranged between 80 and 1,500 ng/l. The quantity of IL-12 in the serum was estimated from a calibration curve, which ranged between 2 and $40 \mathrm{pg} / \mathrm{ml}$.

Detection of caspase-3, Bcl2 and Bax in spleen. The spleens were quickly removed and placed into liquid nitrogen. Frozen samples were reserved at $-80^{\circ} \mathrm{C}$ until further analysis. The spleen organs were homogenized with glass-Teflon ${ }^{\circledR}$. Total RNA was prepared from the splenic organ $(100 \mathrm{mg})$ with TRIzol ${ }^{\circledR}$ reagent (Invitrogen Life Technologies, Carlsbad, CA, USA) according to the manufacturer's instructions. Complementary DNA (cDNA) was synthesized with a First Strand cDNA Synthesis kit (Thermo Fisher Scientific Inc., Waltham, MA, USA). Reverse transcription-polymerase chain reaction (PCR) was carried out using a Maxima SYBR-Green PCR kit (Thermo Fisher Scientific Inc.) with indicated primers. After an initial $10 \mathrm{~min}$ at $95^{\circ} \mathrm{C}$, the PCR program was finished as follows: $95^{\circ} \mathrm{C}$ for $15 \mathrm{sec}, 60$ or $57^{\circ} \mathrm{C}$ for $30 \mathrm{sec}$ and extension at $72^{\circ} \mathrm{C}$ for $30 \mathrm{sec}$, for 40 cycles. At the end of the reaction, melting curve analysis was performed to ensure the specificity of the reaction. $\beta$-actin was used as an internal control and primers used for the PCR are shown in Table I. 


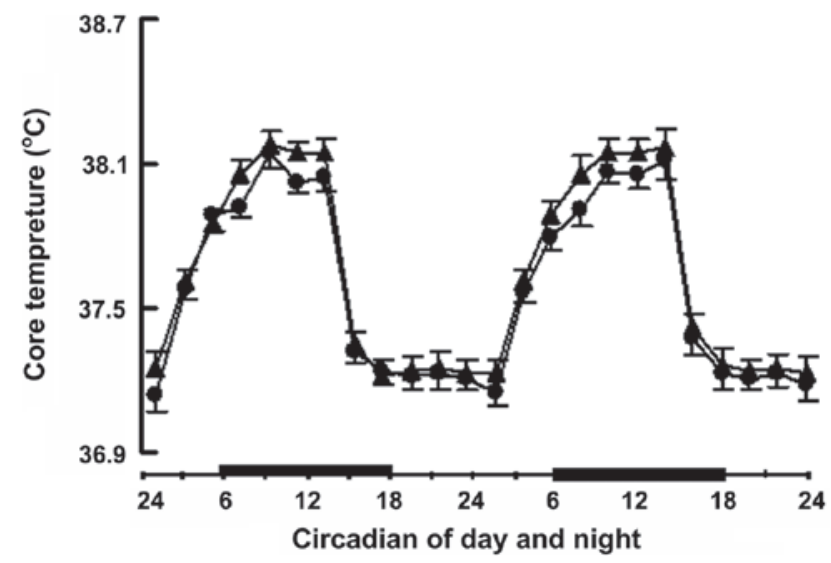

Figure 1. Effect of heat exposure on body's core temperature. The body core temperature of the rats in the control group $\left(24^{\circ} \mathrm{C}\right.$, black circles) and heat exposure group $\left(32^{\circ} \mathrm{C}\right.$, black triangle). The rectangular black box represents the dark (night) cycle.

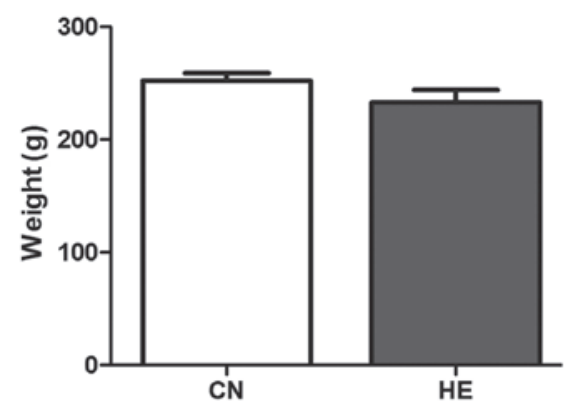

Figure 2. Effect of heat exposure on rats' weight. All the data are shown as mean \pm standard deviation $(n=8)$. $\mathrm{CN}$, control group; HE, heat exposure group.

Statistical analysis. All the data were analyzed by SPSS, Inc., (version 21.0; IBM Corp., Armonk, NY, USA), and the results are represented as mean \pm standard deviation. The statistical difference was evaluated using the t-test. $\mathrm{P}<0.05$ and $\mathrm{P}<0.01$ were considered to indicate a statistically significant difference.

\section{Result}

Body core temperature of rats. The dynamic change of the body core temperature of Sprague-Dawley rats showed that the body's core temperature in the two groups was lower in the daylight and higher at night, but there was no statistical significance between the two groups (Fig. 1).

Body weight and organ coefficient. The body weight was reduced in the HE group, but no statistical significance was observed ( $P>0.05$ ) (Fig. 2). The organ coefficient of the pituitary in the HE group was increased significantly compared to the $\mathrm{CN}$ group $(\mathrm{P}<0.05)$ (Fig. 3), and the organ coefficient of the adrenal glands was evidently higher than that of the $\mathrm{CN}$ group $(\mathrm{P}<0.05)$ (Fig. 4).

Serum ACTH and Cor concentrations. Compared with the CN group, the serum $\mathrm{ACTH}$ level was higher $(\mathrm{P}<0.05)($ Fig. 5) and the Cor level increased significantly $(\mathrm{P}<0.01)$ (Fig. 6) in the HE group.

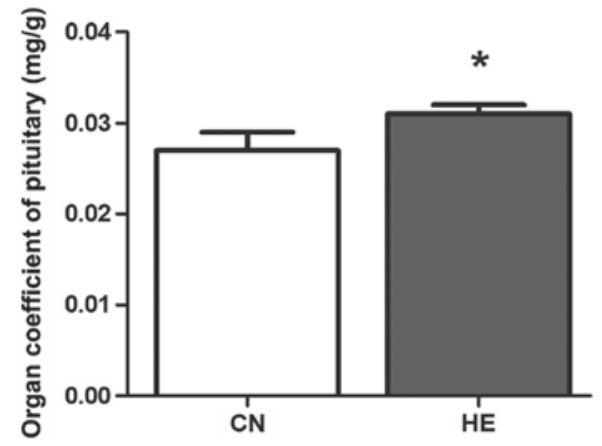

Figure 3. Effect of heat exposure on the organ coefficient of the pituitary gland. All the data are shown as mean \pm standard deviation $(n=8)$. ${ }^{*} \mathrm{P}<0.05$ compared to $\mathrm{CN}$. $\mathrm{CN}$, control group; $\mathrm{HE}$, heat exposure group.

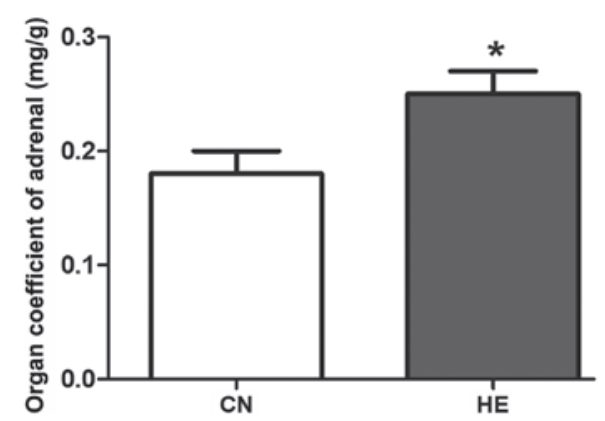

Figure 4. Effect of heat exposure on the organ coefficient of adrenal gland. All data are shown as mean \pm standard deviation $(n=8) .{ }^{*} \mathrm{P}<0.05$ compared to CN. CN, control group; HE, heat exposure group.

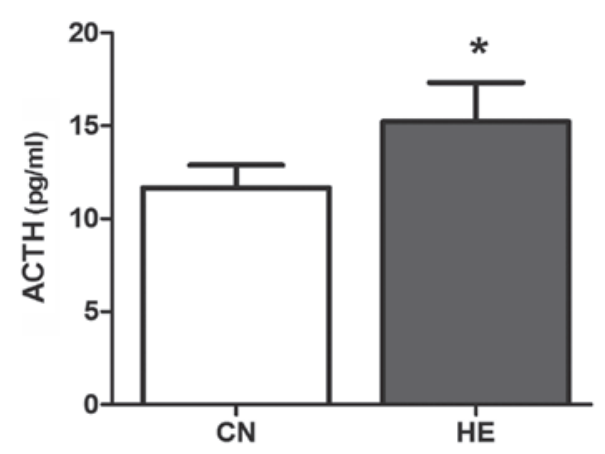

Figure 5. Effect of heat exposure on the level of adrenocorticotropic hormone $(\mathrm{ACTH})(\mathrm{pg} / \mathrm{ml})$ in the serum of rats. All the data are shown as mean \pm standard deviation $(n=8)$. ${ }^{*} \mathrm{P}<0.05$ compared to $\mathrm{CN}$. $\mathrm{CN}$, control group; HE, heat exposure group.

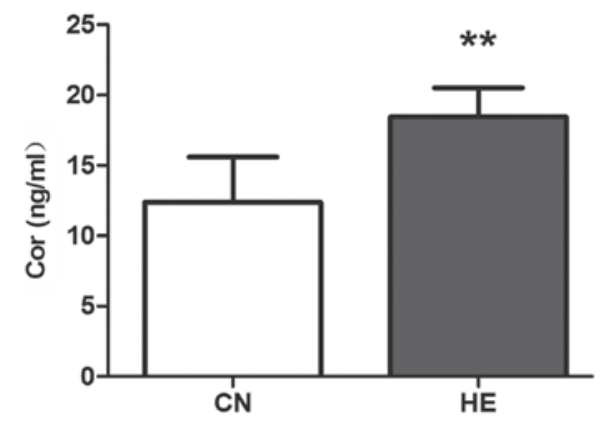

Figure 6. Effect of heat exposure on the level of cortisol (Cor) (ng/ml) in the serum of rats. All the data are shown as mean \pm standard deviation $(n=8)$. ${ }^{* *} \mathrm{P}<0.01$ compared to $\mathrm{CN}$. CN, control group; HE, heat exposure group. 


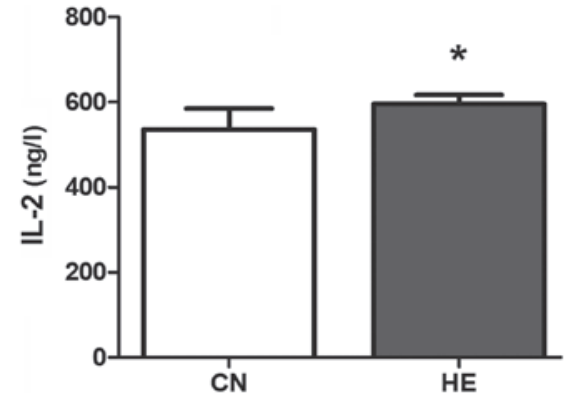

Figure 7. Effect of heat exposure on the level of interleukin-2 (IL-2) (ng/l) in the serum of rats. All the data are shown as mean \pm standard deviation $(n=8)$. ${ }^{*} \mathrm{P}<0.05$ compared to $\mathrm{CN}$. CN, control group; HE, heat exposure group.

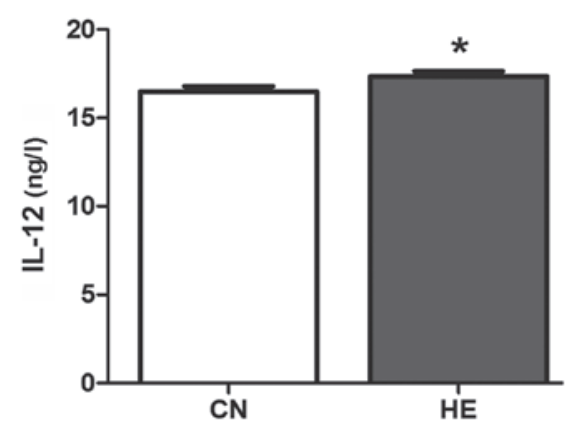

Figure 8. Effect of heat exposure on the level of interleukin-12 (IL-12) $(\mathrm{ng} / \mathrm{ml})$ in serum of rats. All the data are shown as mean \pm standard deviation $(\mathrm{n}=8) .{ }^{*} \mathrm{P}<0.05$ compared to $\mathrm{CN}$. $\mathrm{CN}$, control group; HE, heat exposure group.

Serum IL-2 and IL-12 concentrations. The serum IL-2 in the $\mathrm{HE}$ group is higher than that of the $\mathrm{CN}$ group $(\mathrm{P}<0.05)$ (Fig. 7), and the level of IL-12 is significantly higher than that of the $\mathrm{CN}$ group $(\mathrm{P}<0.01)($ Fig. 8).

Apoptosis gene expression. The expression of Bcl2 significantly reduced $(\mathrm{P}<0.01)$ in the HE group, and there was no significant difference in the reduction of caspase-3 and Bax between the two groups $(\mathrm{P}>0.05)$ (Fig. 9).

\section{Discussion}

The present study demonstrated that moderate heat stress can cause the body's stress response, enhance immune function and defend against adverse stimulation from the outside.

As the heat stress occurs, there will be a multiple axis reaction in the endocrine system (13), such as the HPA, the hypothalamus-pituitary-thyroid axis or the hypothalamus-pituitary-gonadal axis. Among them, the main feature of the stress reaction is the activation of the HPA axis leading to the increase of ACTH and Cor (14). ACTH is one of the important pituitary hormones, mainly produced in the pituitary. The main physiological function of ACTH is promoting the growth and development of adrenal cortex and stimulating the synthesis and secretion of glucocorticoid. Cor is the terminal product of the HPA axis, one of the adrenal cortical synthetic glucocorticoid (15). Therefore, the secretion of Cor depends on the integrity of the HPA axis. Following the activation of the HPA axis, the anterior pituitary secretes ACTH and the adrenal cortex secretes Cor in a few minutes to affect the

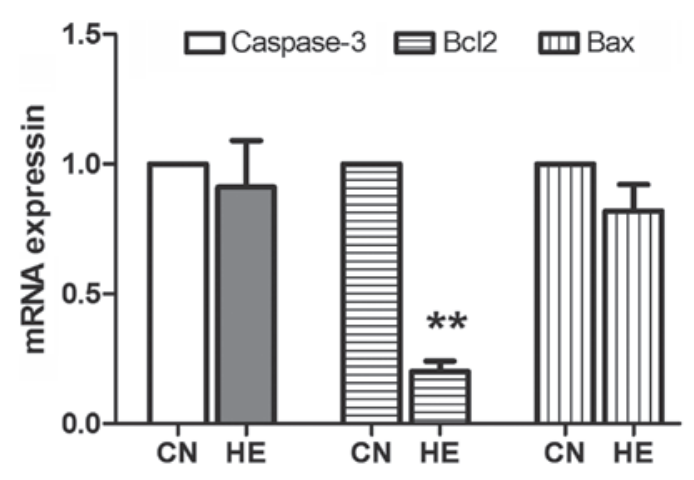

Figure 9. Effect of heat exposure on the expression of apoptosis genes. After standardization, the value is 1 in the control group. All the data are shown as mean \pm standard deviation $(\mathrm{n}=8)$. ${ }^{* *} \mathrm{P}<0.01$ compared to $\mathrm{CN}$. $\mathrm{CN}$, control group; HE, heat exposure group.

behavior and neuroendocrine activities associated with the stress. Therefore, ACTH and Cor are often considered as the most classic and important indicators in studying stress $(16,17)$. In the present study, the serum ACTH and Cor levels increased in the HE group, which indicated that the HPA axis of rats was activated in the process of exposure. The viscera coefficient is the ratio of viscera weight and body weight. Under normal circumstances, the viscera coefficient is relatively constant. The index of the organ coefficient is commonly used in experiments, as this method is simple and sensitive. The increased activity of organs leads to the relative hyperplasia to adapt the heat stress response. Under the environment of the high temperature, the HPA axis was activated in the stress response in the present study.

ACTH is released from the pituitary gland and immune cells. In various immune cells, such as the rat thymus cells, spleen cells, T cells and B cells, immune ACTH and precursor are identified indicating that the HPA axis is closely associated with the cellular immune function. ACTH regulates the production of IL-2 and regulates the immune system by ACTH receptors expressed on immune cells (18-20). IL-2 is mainly produced by $\mathrm{T}$ cells or the $\mathrm{T}$ cell line, and it plays an important role in the immune adjustment. The level of IL-2 reflects the activity of T cells. IL-2 as a heat-trapping factor can be applied to the hypothalamus to cause a high body temperature (21). IL-12 is a cytokine with a broad range of biological activities, and is mainly produced by the activated inflammatory cells. IL-12 promotes T cell proliferation, enhances the activity of NK cells and T cells, and induces tumor necrosis factor and interferon. In the present study, the serum IL-2 and IL-12 in the $\mathrm{HE}$ group is higher than that of the $\mathrm{CN}$ group suggesting that the body's immune function will increase, due to the activation of the HPA axis, to adapt the adverse environment.

The constant body temperature is extremely important in maintaining the normal function of the human body, as biochemical cell and enzymatic reactions are affected by the temperature (22). When the temperature of the cell is reduced, the metabolic activity and function will be limited; and by contrast, increased body temperature enhances the cellular biochemistry. However, when the body temperature is $>42^{\circ} \mathrm{C}$, it will cause the denaturation of intracellular enzymes and other proteins, which leads to cell damage (23). According to a recent study, tissue and organ damage occurs during the 
heat stress period, particularly the immune organ (24). In general, cell death can be divided into two patterns, necrosis and apoptosis. Apoptosis plays an important regulatory role in the body, as it not only ensures the normal development of the body and maintains a stable internal environment, but also affects tumorgenesis and development (25). Caspase-3 is believed to be the important apoptosis practitioner, as its activation is a sign of the irreversible apoptosis stage (26). Bcl2 and $\mathrm{Bax}$ are important members of the $\mathrm{Bcl} 2$ protein family. Increased Bax promotes cell apoptosis, and increased $\mathrm{Bcl} 2$ inhibits cell apoptosis (27). The present study demonstrated that under the condition of short-term heat exposure, stimulation is insufficient to cause the apoptotic program to start and rats can maintain a constant body temperature. These results indicate that the cell survival and biochemical reactions were not affected by the heat exposure process.

The present study showed a significant increase in the serum concentration of ACTH, Cor, IL-2 and IL-12 of rats exposed to short-term heat stress. In addition, the organ coefficients associated with stress were increased and the apoptosis process did not commence. In conclusion, moderate heat stress can causes certain beneficial changes and increase the immune function of the body.

\section{Acknowledgements}

The present study was supported by the Ningxia Natural Science Foundation Key Project (grant no. NZ13055).

\section{References}

1. Shi YJ, Yu JR, Cen XN, Zhu Q and Ren HY: Influence of HSP70 on combined method of hyperthermia and immunologic effector cells to treat cancer. Beijing Da Xue Xue Bao 37: 175-178, 2005 (In Chinese).

2. Maglara AA, Vasilaki A, Jackson MJ and McArdle A: Damage to developing mouse skeletal muscle myotubes in culture: Protective effect of heat shock proteins. J Physiol 548: 837-846, 2003.

3. Kim Y, Kim J, Kim M, Baek W and Kim I: Effect of heat shock on the vascular contractility in isolated rat aorta. J Pharmacol Toxicol Methods 42: 171-174, 1999.

4. Atkinson HC, Wood SA, Kershaw YM, Bate E and Lightman SL: Diurnal variation in the responsiveness of the hypothalamic-pituitary-adrenal axis of the male rat to noise stress. J Neuroendocrinol 18: 526-533, 2006.

5. Dong Q and Liu X: Effect of fear stress in rats on the contents of ACTH, CORT, IL 2, IL 8. J Mol Diagn Ther 5: 173-176, 2013.

6. Watanabe T, Fujioka T, Hashimoto M and Nakamura S: Stress and brain angiotensin II receptors. Crit Rev Neurobiol 12: 305-317, 1998.

7. Padgett DA and Glaser R: How stress influences the immune response. Trends Immunol 24: 444-448, 2003.

8. Fadok VA, Bratton DL and Henson PM: Phagocyte receptors for apoptotic cells: Recognition, uptake and consequences. J Clin Invest 108: 957-962, 2001.
9. Urban BC, Willcox N and Roberts DJ: A role for CD36 in the regulation of dendritic cell function. Proc Natl Acad Sci USA 98: 8750-8755, 2001.

10. Garrett AT, Creasy R, Rehrer NJ, Patterson MJ and Cotter JD: Effectiveness of short-term heat acclimation for highly trained athletes. Eur J Appl Physiol 112: 1827-1837, 2012.

11. Brazaitis M and Skurvydas A: Heat acclimation does not reduce the impact of hyperthermia on central fatigue. Eur J Appl Physiol 109: 771-778, 2010.

12. Fujii N, Honda Y, Ogawa T, Tsuji B, Kondo N, Koga S and Nishiyasu T: Short-term exercise-heat acclimation enhances skin vasodilation but not hyperthermic hyperpnea in humans exercising in a hot environment. Eur J Appl Physiol 112: 295-307, 2012.

13. Liu X, Cui Y, Yang Y, et al: Study on neuroendocrine mechanism of occurence of cerebral infarction in hypertension rats induced by soaring temperature. Prog Mod Biomed 11: 1428-1431, 2011.

14. Hannon MJ and O'Halloran DJ: Isolated acquired ACTH deficiency and primary hypothyroidism: A short series and review. Pituitary 14: 358-361, 2011.

15. Beléen C, Martínez Fuentes AJ and Gracia Navarro F: Role of SST, COR and ghrelin and its receptors at the endocrine pancreas. Front Endocrinol 3: 114, 2012.

16. Servatius RJ, Beck KD, Moldow RL, Salameh G, Tumminello TP and Short KR: A stress-induced anxious state in male rats: Corticotropin-releasing hormone induces persistent changes in associative learning and startle reactivity. Biol Psychiatry 57: 865-872, 2005.

17. Serra M,Pisu MG, Floris I and Biggio G: Social isolation-induced changes in the hypothalamic-pituitary-adrenal axis in the rat. Stress 8: 259-264, 2005.

18. Clarke BL, Gebhardt BM and Blalock JE: Mitogen-stimulated lymphocytes release biologically active corticotropin. Endocrinology 132: 983-988, 1993.

19. Kravchenco IV and Furalev VA: Secretion of immunoreactive corticotropin releasing factor and adrenocorticotropic hormone by $\mathrm{T}$ - and B-lymphocytes in response to cellular stress factors. Biochem Biophys Res Commun 204: 828-834, 1994.

20. Wermerskirchen AS, LaTocha DH and Clarke BL: Adrenocorticotropic hormone controls Concanavalin A activation of rat lymphocytes by modulating IL-2 production. Life Sci 67: 2177-2187, 2000

21. Horowitz M: From molecular and cellular to integrative heat defense during exposure to chronic heat. Comp Biochem Physiol A Mol Integr Physiol 131: 475-483, 2002.

22. Johnson JS, Boddicker RL, Sanz-Fernandez MV, Ross JW, Selsby JT, Lucy MC, Safranski TJ, Rhoads RP and Baumgard LH: Effects of mammalian in utero heat stress on adolescent body temperature. Int J Hyperthermia 29: 696-702, 2013.

23. Khajavi M, Rahimi S, Hassan ZM, Kamali MA and Mousavi T: Effect of feed restriction early in life on humoral and cellular immunity of two commercial broiler strains under heat stress conditions. Br Poult Sci 44: 490-497, 2003.

24. Kanikowska D, Sato M, Sugenoya J, Iwase S, Shimizu Y, Nishimura $\mathrm{N}$ and Inukai $\mathrm{Y}$ : No effects of acclimation to heat on immune and hormonal responses to passive heating in healthy volunteers. Int J Biometeorol 56: 107-112, 2012.

25. Johnstone RW, Ruefli AA and Lowe SW: Apoptosis: A link between cancer genetics and chemotherapy. Cell 108: 153-164, 2002.

26. Fesik SW and Shi Y: Structural biology. Controlling the caspases. Science 294: 1477-1478, 2001.

27. Liu Y, Zheng Q, Wu H, et al: The effects on expression ratio of $\mathrm{Bax} / \mathrm{Bcl}-2$ and the expression of activated caspace 3 in different types of tumor cells. Tumor 33: 138-145, 2013. 